\title{
ANTROPOLINGUISTIK (Hubungan Budaya dan Bahasa)
}

\author{
Felta Lafamane \\ feltafamane@gmail.com
}

\begin{abstract}
Abstrak
Budaya dan bahasa menurut para ahli memiliki keterkaitan yang amat erat. Keeratan hubungan antara bahasa dengan kebudayaan telah lama dirasakan para linguis dan antropoloog sehingga pembicaraan mengenai relasi kedua bidang itu bukanlah topik baru dalam dunia ilmiah. Banyak pandangan yang telah diberikan para ahli mengenai hubungan kedua bidang itu. Dalam mengetahui hubungan anatara keduanya maka muncullah ilmu antropolinguistik, dimana ilmu ini menggabungkan anatara ilmu antropologi dan linguistik. Antropolinguistik adalah ilmu yang menggabungkan antara antropologi (ilmu kebudayaan) dengan linguistic dalam cabang linguistik ilmu ini mempelajari fariasi dan penggunaan bahasa dalam hubungannya dengan perkembangan waktu, perbedaan tempat komunikasi, sistem kekerabatan, pengaruh kebiasaan etnik, kepercayaan, adat istiadat, etika berbahasa, dan pola-pola kebudayaan lain dari suku bangsa. Antropolingistik ini lebih menitikberatkan pada hubungan antara bahasa dan kebudayaan didalam suatu masyarakat seperti peranan bahasa didalam mempelajari bagaimana hubungan keluarga diekspresikan dalam terminologi budaya.
\end{abstract}

Keyword: antropolinguistik, bahasa, budaya, kebudayaan

\section{Abstract}

Culture and language according to experts have a very close relationship. The closeness of the relationship between language and culture has long been felt by linguists and anthropologists, so the discussion of the relations between the two fields is not a new topic in the scientific world. Many views have been given by experts regarding the relationship between the two fields. In knowing the relationship between the two, anthropolinguistic science emerges, where this science combines anthropology and linguistics. Anthropolinguistics is the science that combines anthropology (linguistics) with linguistics in this branch of linguistics studying the variation and use of language in relation to the development of time, differences in communication places, kinship systems, the influence of ethnic customs, beliefs, customs, language ethics, and patterns other cultural patterns of ethnic groups. Anthropolingistics is more focused on the relationship between language and culture in a society such as the role of language in learning how family relationships are expressed in cultural terminology.

Keyword: anthropolinguistics, language, culture, culture 


\section{Antropolinguistik}

Antropologi adalah ilmu yang mempelajari manusia dan kebudayaan secara menyeluruh. Di satu pihak manusia adalah pencipta kebudayaan, di pihak lain kebudayaan yang "menciptakan" manusia sesuai dengan lingkungannya. Dengan demikian, terjalin hubungan timbal balik yang sangat erat dan padu antara manusia dan kebudayaan. Dalam kebudayaan, bahasa menduduki tempat yang unik dan terhormat. Selain sebagai unsur kebudayaan, bahasa juga berfungsi sebagai sarana terpenting dalam pewarisan, pengembangan dan penyebarluasan kebudayaan.

Secara sederhana dapat disebutkan bahwa antropologi linguistik (linguistic anthropology), atau di Indonesia sering disebut Antropolinguistik adalah kajian tentang manusia dan kebudayaan yang terkait dengan fungsi kebahasaan dan dinamika yang terdapat di dalamnya. Cakupan kajian yang berkaitan dengan bahasa sangat luas, karena bahasa mencangkup hamper semua aktifitas manusia. Hingga akhirnya linguistic memperlihatkan adanya pergerakan menuju kajian yang bersifat multidisplin, salah satunya adalah antropologi linguistik.

Bahasa adalah unsur terpenting guna menggali kesadaran terdalam yang terdapat dalam sebuah kebudayaan. Tanpa bahasa kebudayaan tidak dapat dimaknai unsur-unsur subtilnya. Bahkan kaum pemikir posmodernism menganggap bahwa seluruh konstruksi pengetahuan ditentukan oleh bahasa (all human knowledges are determined by language). Di samping kajian antropologi agama dan antropologi sosial, antropolinguistik adalah disiplin baru yang berkembang menjadi kajian mandiri. Bahasa adalah sistem tanda sentral dalam kebudayaan. Melalui bahasa kita dapat mengidentifikasi dan melihat tandatanda kebudayaan sebuah masyarakat, sehingga bagi Ferdinand De Saussure, filsuf bahasa asal Swiss (26 November 1857 - 22 Februari 1913), mengatakan tidak ada yang dapat diketahui tentang dunia ini di luar bahasa (langage).

Antopologi lingustik adalah salah satu cabang linguistik yang menelaah hubungan antara bahasa dan budaya terutama untuk mengamati bagaimana bahasa itu digunakan sehari-hari sebagai alat dalam tindakan bermasyarakat.(Lauder,2005:231) Antropologi biasa juga disebut etnolinguistik menelaah bahasa bukan hanya dari strukturnya semata tapi lebih pada fungsi dan pemakaiannya dalam konteks situasi social budaya. Kajian antropologi linguistic antara lain menelaah struktur dan hubungan kekeluargaan melalui istilah kekerabatan, konsep warna, pola pengasuhan anak, atau menelaah bagaimana anggota masyarakat saling berkomunikasi pada situasi tertentu seperti pada upacara adapt, lalu menghubungkannya dengan konsep kebudayaannya.

Contoh: tindak tutur pendeta'....dengan ini, kalian saya nyatakan sebagai suami istri...' adlah sebuah tindakan melalui bahasa ysng mempunyai otoritas dalam masyarakat untuk mengukuhkan sepasang pengantin menjadi sepasang suami istri yang sah secara hokum dan terterima oleh masyarakat.

Di Amerika yang melopori ilmu antropologi linguistic adalah Franz Boas, sedangkan di Eropa di pakai istilah etnolinguistik (Duranti,1997). Melalui pendekatan antropologi linguistic, kita mencermati apa yang dilakukan orang dengan bahasa dan ujaran-ujaran yang diproduksi;diam dan gesture dihubungkan 
dengan konteks pemunculannya (Duranti,2001:1). Malinowski (dalam Hymes, 1964:4) mengemukakan bahwa melalui etnolinguistik kita dapat menelusuri bagaimana bentuk-bentuk linguistic dipengaruhi oleh aspek budaya, social, mental, dan psikologis; apa hakekat sebenarnya dari bentuk dan makna serta bagaimana hubungan keduanya. Penggunaan bahasa dalam berkomunikasi cenderung dipandang sebagai fungsi kontrol atau suatu tindakan untuk saling mempengaruhi partisipan dalam suatu pertuturan.

Budaya Indonesia sendiri dilihat melalui interdisipliner antropolinguistik, ditegaskan bahwa sistem nilai budaya Indonesia mempunyai pengaruh yang besar atas penggunaan kata ganti orang atau pronominanya. Sesuai dengan teori komunikasi, komunikator dan komunikan komitmen dalam hubungan simetris atau hubungan asimetris. Terjadinya hubungan simetris karena ada kesamaan status sosial, perbedaan mengakibatkan kehadiran asimetris.

Pronomina ketiga tunggal ia/dia berlaku dalam hubungan simetris, namun kata beliau yang fungsinya sama dengan ia/dia hanya dipakai untuk asimetris sehubungan nilai budaya hormat. Kata beliau diperuntukkan terhadap dia yang status sosialnya tinggi: Baru-baru ini Presiden SBY mengunjungi kedua SD Negeri. (1) la sempat mengajar anak-anak. (2) Beliau sempat mengajar anak-anak. Kalimat (1) diucapkan oleh orang yang baru belajar. Walaupun pronomina I saya, aku bersinonim, dalam praktik aplikasinya berbeda. Sebab timbul hubungan simetris/asimetris terhadap pronomina saya, "Permisi, Pak, saya akan membezuk anak sedang sakit," kata pegawai kepada atasannya. "Aku tak sanggup menyelesaikan soal akhir, Bu" ujar siswa kelas 3 SMA kepada gurunya, tidak tahu adat, menganggap dirinya setaraf.

Pronomina kami mempunyai arti (a) komunikator jamak seperti "Ayah, ibu, adik tergabung menjadi Kami bertiga akan berpiknik; (b)sama dengan makna saya ialah honorifiks mayestatis. Biasanya komunikator bertindak sebagai ketua/ wakil ketua/ pemimpin/ kepala misal "Kami (=saya) mengucapkan selamat atas kehadiran bapak/ibu," kata direktur SMA. Tetangga berujar, "Kami tidak mengizinkan ibumu lewat sini." Salah penggunaannya pada pronomina kita terlibat komunikator beserta komunikan hubungannya simetris, marilah kita bersikap dewasa," kata ayahnya membujuk anaknya. Khusus untuk pronomina jamak kami tidak melibatkan komunikan hanya jumlah komunikator banyak..

\section{Antropolinguistik, Bahasa dan Kebudayaan}


Setiap ilmu pengetahuan lazim dibagi atas bidang-bidang cabang-cabang, misalnya, ilmu kimia dibagi atas kimia organic dan anorganik. Atau ilmu psikologi dapat dibagi antara lain atas psikologi klinis dan psikologi social. Memamng setiap ilmu pengetahuan meliputi bahan yang luas sekali, dan demi alas an praktis para ahli suka membagi ilmunya menjadi berbagai bidang bawahan atau cabang ilmunya. Demikian ilmu linguistik lazimnya dibagi menjadi bidang bawahan yang bermacam-macam. Misalnya saja, ada Antropologi Linguistik, yaitu cara penyelidikan linguistik yang dimanfaatkan oleh para ahli Antropologi Budaya.

Antropologi Sosial-Budaya atau lebih sering disebut Antropologi Budaya berhubungan dengan apa yang sering disebut dengan Etnologi. Ilmu ini mempelajari tingkah-laku manusia, baik itu tingkah-laku individu atau tingkah laku kelompok. Tingkah-laku yang dipelajari disini bukan hanya kegiatan yang bisa diamati dengan mata saja, tetapi juga apa yang ada dalam pikiran mereka. Pada manusia, tingkah-laku ini tergantung pada proses pembelajaran. Apa yang mereka lakukan adalah hasil dari proses belajar yang dilakukan oleh manusia sepanjang hidupnya disadari atau tidak. Mereka mempelajari bagaimana bertingkah-laku ini dengan cara mencontoh atau belajar dari generasi diatasnya dan juga dari lingkungan alam dan sosial yang ada disekelilingnya Hipotesis Sapir-Whorf saat itu mengatakan bahwa manusia terkungkung oleh bahasa.

Bahasalah yang mempengaruhi pandangan hidup manusia. Manusia tidak dapat berpikir kecuali melalui bahasanya. Suatu pandangan yang sudah lama ditinggalkan orang, tetapi masih tetap menarik untuk diperbincangkan.Pandangan yang mungkin lebih banyak bisa diterima orang sampai sekarang adalah pandangan sebaliknya, yakni pandangan yang menganggap bahwa kebudayaan atau masyarakatlah yang mempengaruhi bahasa.

Antropolinguistik adalah cabang linguistik yang mempelajari variasi dan penggunaan bahasa dalam hubungannya dengan perkembangan waktu, perbedaan tempat komunikasi, sistem kekerabatan, pengaruh kebiasaan etnik, kepercayaan, etika bahasa, adat-istiadat, dan pola-pola kebudayaan lain dari suatu suku bangsa. Antropolinguistik menitikberatkan pada hubungan antara bahasa dan kebudayaan di dalam suatu masyarakat seperti peranan bahasa di dalam mempelajari bagaimana cara seseorang berkomunikasi dengan orang lain dalam kegiatan sosial dan budaya tertentu, dan bagaimana cara seseorang berkomunikasi dengan orang lain secara tepat sesuai dengan konteks budayanya, bagaimana bahasa masyarakat dahulu sesuai dengan perkembangan budayanya ( Bandingkan Crystal, 1989:412)

Kemungkinan kepunahan bahasa bisa saja terjadi karena masyarakat sudah sekian lama melunturkan budayanya. Dengan melihat salah satu sisi dalam pemakaian "nama" dan gelar kepemimpinan saja dapat mempengaruhi budaya masyarakat atau sebaliknya.

Misalkan, bahasa Sunda yang memiliki berbagai dialek dan susunan kata bahasa kerap kali dikaburkan penuturnya dengan objek atau subjek yang berbeda. Istilah "abah" sering ditujukan pada kakek. Padahal, kata "abah" adalah kata serapan dari bahasa Arab yang ditujukan untuk orang tua (bapak), yaitu "aba" atau "abun", "ya'ba", "abah". Di Tasikmalaya, misalnya, istilah "abah" ditemukan "abah sepuh" (bapak tua) dan "abah anom" (bapak muda). Sementara itu, di Banten lebih menggunakan "bapak kolot" (kakek). Kiranya, penuturan kata seperti itu dalam masyarakat jawa bukan dilihat hanya faktor usia, tapi 
dinisbatkan kepada orang-orang yang memang "dituakan" masyarakat, misalnya karena menjadi panutan. Berbeda dengan kata "abu" (bukan nama seseorang) yang bersinonim dengan kata "embah". Di Bogor, kata "abu" ditujukan untuk perempuan yang sudah tua (nenek). Penuturan seperti itu mungkin sudah menyalahi aturan bahasa, tapi itulah kenyataannya. Seperti halnya dalam panggeugeut (bhs Sunda), nama "Muhammad" menjadi "Mamat" (kadangkala Memet) yang dilihat dari maknanya akan terlihat jauh. "Muhammad" artinya "terpuji" berarti pula diambil dari nama nabi, sedangkan "Mamat" artinya "mati". Dilihat dari akar bahasanya (bahasa Arab), sebenarnya kata "umi" dan "mamah" memiliki persamaan yang berarti "ibu". Kata "ibu" bisa juga penyimpangan dari kata "abu", begitu seterusnya.Itulah fakta kerancuan bahasa yang terjadi di sekitar kita pada umumnya. Dan apabila dikatakan telah terjadi kepunahan, sesungguhnya telah lama terjadi. Pergaulan masyarakat Indonesia dengan suku-suku bangsa dan agama di dunia masa lalu telah mengakibatkan masyarakat banyak menyerap bahasa Asing ke dalam bahasa sehari-hari, termasuk untuk identitas diri. Misal, karena masuknya (para pedagang Arab) Islam abad ke-9 H/14 M, masyarakat banyak mengubah nama ke-Arabarab-an.

Sistem budaya asing juga merupakan salah satu penyebab pluralitas budaya. Contohnya yaitu bahasa asing yang masuk di Indonesia. bahasa India contohnya yang telah masuk sejak zaman kerajaan kuno. bahasa India sangat mempengaruhi bahasa di Bali. bahasa Arab berpengaruh bagi bahasa Jawa, bahasa Melayu berpengaruh pada bahasa Aceh dan sekitarnya dan bahasa Cina pada bahasa Betawi.

Kalau begitu, apa yang menjadi kekhususan ilmu linguistik? Ahli linguistik berurusan dengan bahasa sebagai bahasa. Itulah "objek" nya. Jadi ahli linguistik tidak berurusan dengan bahasa sebagai sifat khas golongan social, atau bahasa sebagai alat prosedur pengadilan. Hal tersebut masing-asing menjadi urusan ahli psikologi, ahli sosiologi atau ahli hukum. Yang menjadi kekhususan ilmu linguistik adalah bahasa sebagai bahasa.

Ilmu-ilmu seperti psikologi, sosiologi antropologi, dan lain sebagainya, sering di sebut ilmu "empiris". Artinya, ilmu-ilmu tersebut berdasarkan "fakta" dan "data" yang dapat diuji oleh ahli tertentu dan juga oleh semua ahli lainnya. Demikian pula halnya dengan ilmu linguistik.

Hubungan bahasa dengan kebudayaan memang erat sekali. Mereka saling mempengaruhi, saling mengisi, dan berjalan berdampingan. Yang paling mendasari hubungan bahasa harus kebudayaan adalah bahasa harus dipelajari dalam konteks kebudayaan dan kebudayaan dapat dipelajari melalui bahasa. Kajian atau pembicaraan hubungan keduanya pada umumnya dilihat dari ilmu yang mempelajarinya, yakni Antropologi sebagai ilmu yang mengkaji kebudayaan dan linguistik sebagai ilmu yang mengkaji bahasa. Linguistik (ilmu bahasa) dan Antropologi Kultural (ilmu Budaya) bekerja sama dalam mempelajari hubungan bahasa dengan aspek-aspek budaya.

Antropolinguistik juga mempelajari unsur-unsur budaya yang terkandung dalam pola-pola bahasa yang dimiliki oleh penuturnya serta mengkaji bahasa dalam hubungannya dengan budaya penuturnya secara menyeluruh. Dalam kaitannya dengan materi linguistik kebudayaan, Beratha (1998:45) mengatakan bahwa kajian linguistic kebudayaan memfokuskan kajiannya pada makna alamiah metabahasa dan 
terdiri atas kajian kebudayaan, kajian komunikasi lintas budaya, kajian etnografi berbahasa, serta kajian kebudayaan dan perubahan bahasa (linguistik diakronis).

Dengan mendengar istilah Antropolinguistik, paling sedikit ada tiga relasi penting yang perlu diperhatikan. Pertama, hubungan antara satu bahasa dengan satu budaya yang bersangkutan. Artinya, ketika kita mempelajari suatu budaya, kita juga, bahkan harus mempelajari bahasanya dan ketika kita mempelajari budayanya. Kedua, hubungan antara bahasa dengan budaya secara umum. Dalam hal ini, kita tahu bahwa setiap ada satu bahasa dalam satu masyarakat, maka ada satu budaya dalam masyarakat itu. Bahasa mengindikasikan budaya: perbedaan bahasa berarti perbedaan budaya atau sebaliknya. Oleh karena itu, penghitungan bahasa seolah-olah relevan dengan penghitungan budaya bahkan penghitungan etnik. Ketiga, hubungan antara linguistik sebagai ilmu bahasa dengan antropologi sebagai ilmu budaya.

Menurut Segall dkk (1967) bahwa istilah emik-etik pada mulanya dicetuskan oleh Pike (1966) yang kemudian disepakati hingga sekarang oleh para sarjana psikologi lintas budaya. Pike mula-mula melihat adanya gagasan yang sejalan dalam pendekatan antara rumusan dan pengetrapan teori dengan fonetik dan fonemik. Dalam bidang linguistik, fonemik adalah mempelajari pola-pola bunyi yang digunakan dalam suatu bahasa tertentu. Sedangkan fonetik mencoba untuk mengeneralisir hasil-hasil penelitian fonemik dari berbagai bahasa menjadi satu patokan pola-pola bunyi untuk semua bahasa. Dari fonemik dan fonetik Pike mencopot istilah etik dan emik. Berry (1969) merangkum komentar-komentar Pike pada pemilahan emik-etik sebagaimana yang dipakai dalam psikologi,

Bahasa yang berbeda sangat menyulitkan masyarakat yang berkunjung ke daerah yang lain. Misalnya seorang Bugis yang datang ke Bali. Tentu sangat sulit untuk melakukan komunikasi. Atau ada pemberitahuan yang disampaikan kepada khalayak ramai dengan menggunakan bahasa daerah, tentu menimbulkan kesalahpahaman bagi pihak yang tidak mengerti.

Peranan bahasa sangat penting dalam memahami kebudayaan, dan peranan kebudayaan juga sangat penting dalam memahami bahasa. Banyak terjadi kekeliruan, kesalahpahaman, bahkan perselisihan karena orang tidak dapat menggunakan bahasa yang sesuai dengan budaya peserta komunikasi. Di sisi lain, kemarahan dapat menjadi reda apabila salah satu peserta komunikasi dapat menggunakan bahasa yang santun dan mencerminkan budi yang baik. Secara singkat, dapat dikatakan bahwa komunikasi melalui bahasa akan mencapai sasarannya apabila peserta komunikasi menempatkan bahasa didalam konteks budayanya.

\section{Hubungan Bahasa dan Kebudayaan}

Keeratan hubungan antara bahasa dengan kebudayaan telah lama dirasakan para linguis dan antropolog sehingga pembicaraan mengenai relasi kedua bidang itu bukanlah topik baru dalam dunia ilmiah, dibawah ada beberapa hubungan bahasa dengan kebudayaan :

1.Bahasa sebagai alat atau sarana kebudayaan. 
Dalam hubungan ini, bahasa berperan sebagai alat atau sarana kebudayaan, baik untuk perkembangan, transmisi maupun penginventarisannya. Kebudayaan Indonesia dikembangkan melalui bahasa Indonesia. Pemerkaan khazanah kebudayaan Indonesia melalui kebudayaan daerah dan kebudayaan asing, misalnya, dilakukan dengan menggunakan dengan menggunakan bahasa Indonesia. Khazanah kebudayaan Indonesia tersebut juga disebarkan atau dijelaskan melalui bahasa Indonesia sebab penerimaan kebudayaan hanya bisa terwujud apabila kebudayaan itu dimengerti, dipahami, dan dijunjung masyarakat pemilik kebudayaan itu sendiri. Dengan demikian, bahasa memainkan peranan penting. Bahkan, sering dinyatakan bahwa kebudayaan dapat terjadi apabila bahasa ada karena bahasalah yang menginginkan terbentuknya kebudayaan.

Bahasa digunakan sebagai ekspresi nilai-nilai budaya. Nilai-nilai budaya yang dapat disampaikan oleh bahasa sebagai jalur penerus kebudayaan terbagi atas tiga bagian kebudayaan yang saling berkaitan, kebudayaan ekspresi, kebudayaan tradisi, dan kebudayaan fisik

\section{Bahasa sebagai bagian dari kebudayaan.}

Bahasa dikatakan sebagai bagian dari kebudayaan karena pembendarahan suatu bangsa (Alisyahbana, 1979) ialah jumlah kekayaan rohani dan jasmani bangsa yang empunya bahasa itu. Tiap-tiap yang berpikir, tiap-tiap yang berbuat, tiap-tiap yang dialami, malahan tiap-tiap yang ditangkap oleh pancaindra bangsa itu dengan sadar dan yang menjadi pengertian dalam kehidupannya, terjelma dalam kata dan menjadi sebagian dari kekayaan perbendaharaan kata bangsa itu. Dan kata yang berpuluhpuluh dan berates-ratus ribu jumlahnya itu sekali lihat rupanya terpisah-pisah dan cerai-berai, tetapi pada hakikatnya merupakan suatu kesatuan kebudayaan bangsa yang empunya bahasa itu.

\section{Bahasa merupakan hasil dari kebudayaan.}

Dikaitkan bahwa bahasa (Levi-Strauss, 1972:68) merupakan hasil kebudayaan. Artinya, bahasa yang dipergunakan atau diucapkan oleh suatu kelompok masyarakat adalah suatu refleksi atau cermin keseluruhan kebudayaan masyarakat tersebut. Pada pelaksanaan upacara ritual, yang masing-masing menggunakan bahasa. Peristiwa budaya semacam itu akan menghasilkan bahasa.

4.Bahasa hanya mempunyai makna dalam latar kebudayaan yang menjadi wadahnya.

Bentuk bahasa yang sama mempunyai makna yang berbeda sesuai dengan kebudayaan yang menjadi wadahnya. Jika dibandingkan antara 2 dua suku bangsa, kita akan melihat perbedaan makna tersebut.

\section{Bahasa sebagai persyaratan kebudayaan.}

Pengertian bahasa sebagai persyaratan kebudayaan dapat diartikan dalam dua cara. Pertama, bahasa merupakan persyaratan budaya secara diakronis karena kita mempelajari kebudayaan melalui bahasa. Kedua, berdasarkan sudut pandang yang lebih teoritis, bahasa merupakan persyaratan kebudayaan karena materi atau bahan pembentuk keseluruhan kebudayaan, yakni relasi logis, oposisi, korelasi dan sebagainya. 


\section{Bahasa mempengaruhi cara berpikir.}

Bahasa dan berpikir dalam kehidupan manusia adalah dua hal yang sangat mendasar dan saling berhubungan. Kedua hal ini secara khas dan jelas membedakan manusia dari binatang. Dengan bahasa, orang berkomunikasi dengan dirinya sendiri dengan orang lain, sedangkan dengan berpikir, dia dapat memecahkan berbagai masalah kehidupan yang dihadapinya. Berpikir adalah upaya yang kita lakukan dengan jalan mengorganisasikan serta menggunakan berbagai konsep, berbagai pertimbangan, berbagai kebiasaan, dan berbagai kaidah sebelum suatu tindakan dilakukan.

7.Cara berpikir mempengaruhi bahasa.

Sebaliknya, ada anggapan bahwa cara berpikir mempengaruhi cara berbahasa atau dengan kata lain, pikiran yang termasuk kebudayaan mental mempengaruhi bahasa. Dalam hal ini, kebudayaan suatu masyarakat (Wardhaugh, 1986:212) berefleksi di dalam bahasa yang mereka pergunakan. Pikiran (kebudayaan mental) mengarah bahasa menjadi bahasa yang berisi, bermakna, dan bermanfaat. Kerusakan pikiran seseorang akan mempengaruhi bahasanya. Jika pikiran seseorang kacau, maka bahasanya juga akan kacau. Pada suatu saat bahasa seseorang mungkin bagus dan terpelihara, tetapi di saat lain bahasanya kurang terjaga. Hal itu sangat tergantung pada keadaan pikiran ketika dia berbahasa. Mungkin, bahasa orang gila masih dapat dimengerti, tetapi makna, manfaat, dan tujuannya tidak dapat dipahami. Padahal, bahasa sebagai suatu system komunikasi harus dapat dipahami makna dan tujuannya terutama bagi peserta komunikasi (penyapa dan pesapa).

\section{Tata cara berbahasa dipengaruhi norma-norma budaya.}

Hubungan lain yang perlu diperhatikan adalah bahwa di dalam tindak komunikasi, kita tunduk pada norma-norma budaya. Tata cara berbahasa seseorang tidak sesuai dengan norma-norma budaya yang hidup dalam masyarakat tempat hidup dan dipergunakan bahasa tersebut. Apabila tata cara berbahasa seseorang tidak sesuai dengan norma-norma budayanya, maka dia tidak jarang dituduh orang yang aneh, egois, sombong, acuh, tidak beradat atau bahkan tidak berbudaya.

\section{Bahasa ditransmisi secara kultural.}

Artinya, kemampuan berbahasa ditransmisi dari generasi kegenerasi dengan proses belajar dan bukan secara genetik. Pernyataan ini bukanlah menyangkal bahwa anak-anak dilahirkan dengan kemampuan bawaan (batiniah) terhadap bahasa, melainkan menegaskan perbedaan antara bahasa manusia dengan system komunikasi hewan.

10.Kebudayaan merupakan hasil komunikasi.

Inti dasar kebudayaan sebagaimana sudah dijelaskan di atas adalah segala sesuatu dalam rangka kehidupan masyarakat sebagai hasil proses belajar. Sesuatu yang dimaksud di sini adalah ide, tindakan, dan hasil karya manusia. Ketiga-tiganya tercipta dan menjadi bermanfaat dalam kehidupan manusia karena interkasi antar manusia di dalam masyarakat itu. Interaksi manusia hanya akan dapat terwujud apabila terjadi komunikasi. Tiada interaksi tanpa komunikasi. Itulah sebabnya interaksi sering diasosiasikan dengan komunikasi. 
11.Perubahan kebudayaan mempengaruhi perubahan bahasa.

Hubungan antara bahasa dengan kebudayaan yang masih sangat perlu mendapat perhatian adalah mengenai perubahan bahasa yang diakibatkan perubahan budaya. Perubahsan bahasa yang diakibatkan perubahan budaya lebih menonjol pada aspek leksikon (kosakata) daripada aspek-aspek linguistik lain baik mengenai bentuk maupun mengenai makna leksikon itu.

Fungsi :

Fungsi atau tujuan mempelajari antropolinguistik adalah :

1. Menganalisis istilah-istilah budaya atau ungkapan lain (analyzing cultural terms or other expressions).

2. Menganalisis proses penamaan (analyzing naming process).

3. Menganalisis kesopan-santunan (analyzing politeness).

4. Menganalisis konsep budaya dari unsur-unsur bahasa (analyzing cultural concepts from linguistic elements).

5. Menganalisis etnisitas dari sudut bahasa (analyzing etnicity from the view point of language),

6. Menganalisis cara berpikir melalui struktur bahasa (analyzing the way of thinking through the structure of the language).

Unsur-Unsur Bahasa :

Meskipun demikian, hubungan antara penanda dan petanda tidak simbiotis-fungsional. Hubungan kedua bersifat arbriter atau tidak teratur, sembarang, kecelakaan, dan tanpa kesepakatan terlebih dahulu. Dalam bahasa De Saussure disebutkan bahwa ..."tidak ada sesuatu pun yang mencakup apapun pilihan arbriter, untuk kata-kata yang hanya memadai, dan selebihnya adalah peniruan-peniruan yang kurang konvensional dari bunyi-bunyi tertentu. Pun demikian kata-kata memberi peluang kepada katakata lainnya, interjeksi-interjeksi....tidak ada satu prasyarat pun yang pasti antara penanda dan petanda."

Bahasa sebagai tanda juga memiliki komponen-komponen tertentu :

Ikon, adalah hubungan tanda dan acuannya didasarkan kepada hubungan persamaan atau subkemiripan. Contohnya, Mesjid Raya Baiturrahman menjadi ikon Banda Aceh seperti juga Pizza menjadi ikon kuliner dari Italia.

Indeks, adalah hubungan antara tanda yang memiliki kedekatan eksistensi. Sebuah tanda disebut indeks apabila terdapat hubungan yang fenomenal atau eksistensial di dalamnya. Seperti indeks table set for dinner terdiri dari gelas, piring, garpu, sendok, dan pisau. Indeks untuk perguruan tinggi ada mahasiswa, dosen, perpustakaan, ruang kuliah, dsb.

Simbol, adalah hubungan tanda yang terbentuk oleh aspek kultural atau konvensional. Meskipun pemahaman tanda simbolik bersifat konvensional atau kesepakatan, ia sangat tergantung kepada 
kebudayaan penggunanya. Contoh, singa sebagai simbol kejantanan, ular simbol kelicikan dan ketidaksetiaan, merah simbol berani, dsb.

\section{Konsep Bahasa}

Dalam konsep bahasa menurut De Saussure bahasa dibagi kepada tiga bentuk : langage, langue, dan parole.

1. Langage adalah pemahaman yang merujuk kepada sistem kebahasaan manusia secara keseluruhan. Langage tidak berarti apa-apa kecuali sebagai sebuah tanda tentang sistem kebahasaan.

2. Langue adalah bahasa sebagai proses sosial. Langue adalah bahasa yang dipraktikkan masyarakat untuk berbicara dan menulis.

3. Parole adalah sistem kebahasaan yang dipraktikkan individu untuk memproduksi makna tertentu.

Dalam sistem bahasa, parole - lah yang yang banyak berpengaruh dalam memperbaharui bahasa dan tata bahasa. Dalam konsep linguistik modern, parole disebut dengan wacana (discourse). Dalam kajian budaya, anak muda paling banyak membangun sistem parole yang kemudian melahirkan model praktik penandaan harian (signifying rituals and practices of daily life).

Dari konsep tentang tanda inilah kemudian berkembang ilmu baru yang disebut dengan semiotika atau semiologi. Semiotika atau semiologi (orang lebih sering menggunakan istilah semiotika adalah ilmu yang memproyeksikan bahasa sebagai sebuah struktur yang dapat dibedah untuk dimaknai (kembali). Makanya semiotika termasuk dalam kajian strukturalisme.

Namun fungsi semiotika tidak hanya membedah bahasa (linguistik), tetapi juga apa saja yang menjadi fenomena sosial-kebudayaan. Semiotika juga digunakan dalam kajian psikologi, arsitektur, militer, film, hingga fashion. Pengertian struktur dalam kajian ini adalah sebuah sistem transformasi, dimana sistem tersebut dikuasai oleh hukum-hukum tertentu, yang kemudian mempertahankan bahkan memperkayanya. Hal itu karena pola mekanistiknya tidak mendobrak batas-batas sistem itu dan tidak memasukkan unsur-unsur dari luar (Vueger, 1982 : 102).

Makanya strukturalisme merupakan suatu cara pikir tentang dunia yang memberikan perhatian sepenuhnya pada persepsi dan deskripsi suatu struktur. Struktur ini mendasarkan kepada tiga hal yaitu 1) ide tentang keseluruhan, 2) ide tentang transformasi, dan 3) ide tentang regulasi diri (self-regulation). Terence Hawkes, pakar linguistik yang banyak mengkaji karya-karya sastra Shakespeare dan kajian bahasa Inggris, menyebut strukturalisme dalam linguistik adalah totalitas yang koheren dan bersifat internal, yakni penyusunan entitas-entitas yang semestinya utuh pada dirinya sendiri, dan bukan secara sederhana campuran yang dibentuk dari unsur-unsur bebas dari kemungkinan.

Pengertian strukturalisme dalam bahasa (atau dalam kajian sosial-budaya) tidaklah sama dengan pemahaman strukturalisme dalam ilmu teknik atau kimia. Strukturalisme dalam kajian sosial-humaniora 
bersifat dinamis, karena tidak hanya memiliki kemampuan distrukturkan tetapi juga menstrukturkan. Inilah yang disebut sebagai daya transformasi yang ada dalam kajian strukturalisme.

Strukturalisme juga berbeda dengan positivisme. Strukturalisme bersifat dinamis, sedang positivisme bersifat statis. Strukturalisme adalah proses yang terus menapak, sedangkan positivisme adalah hasil final. Strukturalisme membuka diri pada konjungsi dengan dunia luar sedangkan positivisme cenderung menutup diri. Strukturalisme adalah point of departure, sedangkan positivisme adalah point of arrival.

Dan, dalam melakukan pembacaan pada teks ini tidak dapat dipahami dalam kerangka logika positivistik. Anda harus mampu merentangkan imajinasi dan kesadaran asosiatif pada contoh-contoh yang hidup di sekitar. Bukankah seperti tesis di tulisan ini, fungsi bahasa tak lain menangkap fenomena budaya yang di dalam dirinya sendiri adalah sel dinamika, loncatan, titik didih, kontradiksi, dan kompleksitas. Tugas kitalah untuk mengatur kompleksitas itu menjadi sesuatu yang bermakna.

\section{Daftar Pustaka}

Berger, Arthur A., Tanda-tanda dalam Kebudayaan, Yogyakarta : Tiara Wacana, 2000.

Kurniawan, Semiologi Roland Barthes, Magelang : Tera, 2001.

Sibarani, Robert, "Antropolinguistik dan Semiotika", makalah seminar di Lhokseumawe, Maret 2006.

Siregar, Ahmad Samin, "Konsep Kunci Semiotika dan Kaitannya dengan Linguistik", makalah seminar di Lhokseumawe, Maret 2006.

Beratha, Ni Luh Sutjiati.1998 “Materi Linguistik Kebudayaan” dalam Linguistik edisi 9, September 1998. Denpasar: Program Magister (S2) Linguistik, Universitas Udayana. Hal 45.

Koentjaraningrat.1980 Pengantar Antropologi, Jakarta: Aksara Baru.

Amanto, B. S., Umanailo, M. C. B., Wulandari, R. S., Taufik, T., \& Susiati, S. (2019). Local Consumption Diversification. Int. J. Sci. Technol. Res, 8(8), 1865-1869.

Amri, M., Tahir, S. Z. A. B., \& Ahmad, S. (2017). The Implementation of Islamic Teaching in Multiculturalism Society: A Case Study at Pesantren Schools in Indonesia. Asian Social Science, 13(6), 125.

Andini, K. NILAI BUDAYA SUKU BAJO SAMPELA DALAM FILM THE MIRROR NEVER LIES KARYA KAMILA ANDINI.

ARYANA, A. PERBANDINGAN GAYA BAHASA DALAM NOVEL ATHEIS KARYA ACHDIAT KARTA MIHARDJA DAN NOVEL TELEGRAM KARYA PUTU WIJAYA: TINJAUAN STILISTIKA.

Azwan, A. (2018). Politeness strategies of refusals to requests by Ambonese community. LINGUA: Jurnal Bahasa, Sastra, Dan Pengajarannya, 15(1), 1-6. 
Bin-Tahir, S. Z., Atmowardoyo, H., Dollah, S., Rinantanti, Y., \& Suriaman, A. (2018). MULTILINGUAL AND MONO-MULTILINGUAL STUDENTS'PERFORMANCE IN ENGLISH SPEAKING. Journal of Advanced English Studies, 1(2), 32-38.

Bin Tahir, S. Z. (2017). Multilingual teaching and learning at Pesantren Schools in Indonesia. Asian EFL Journal, 89, 74-94.

Bin Tahir, S. Z. (2015). The attitude of Santri and Ustadz toward multilingual education at Pesantren. International Journal of Language and Linguistics, 3(4), 210-216.

Bin-Tahir, S. Z., \& Rinantanti, Y. (2016). Multilingual lecturers' competence in english teaching at the university of Iqra Buru, Indonesia. Asian EFL Journal, 5, 79-92.

Bin-Tahir, S. Z., Saidah, U., Mufidah, N., \& Bugis, R. (2018). The impact of translanguaging approach on teaching Arabic reading in a multilingual classroom. ljaz Arabi Journal of Arabic Learning, 1(1).

Bin-Tahir, S. Z., Bugis, R., \& Tasiana, R. (2017). Intercultural Communication of a Multicultural Family in Buru Regency. Lingual: Journal of Language and Culture, 9(2), 8.

Djamudi, N. L., Nurlaela, M., Nazar, A., Nuryadin, C., Musywirah, I., \& Sari, H. (2019, October). Alternative social environment policy through educational values in Kafi'a's customary speech to the kaledupa community of Wakatobi Island, Indonesia. In IOP Conference Series: Earth and Environmental Science (Vol. 343, No. 1, p. 012118). IOP Publishing.

Djunaidi, F. G., Azwan, A. Y. T., Iye, R., \& bin Tahir, S. Z. Decks Range Gola Village Community Begun District Buton District North.

Indonesia, K. K. D. B. Morfologi Bahasa Indonesia.

Iye, R., \& Susiati, S. (2018). NILAI EDUKATIF DALAM NOVEL SEBAIT CINTA DI BAWAH LANGIT KAIRO KARYA MAHMUD JAUHARI ALI (Educative Values in Sebait Cinta di Bawah Langit Kairo by Mahmud Jauhari Ali). Sirok Bastra, 6(2), 185-191.

lye, R. (2018). Tuturan emosi mahasiswa kota baubau dalam ranah demonstrasi.

Iye, R., Susiati, S., \& Karim, K. (2020). Citra Perempuan dalam Iklan Sabun Shinzui. Sang Pencerah: Jurnal Ilmiah Universitas Muhammadiyah Buton, 6(1), 1-7.

Iye, R. (2018). Tuturan dalam Prosesi Lamaran Pernikahan di Tomia Kabupaten Wakatobi. Jurnal Totobuang, 6(2).

Iye, R. H. NILAI-NILAI MORAL DALAM TOKOH UTAMA PADA NOVEL SATIN MERAH KARYA BRAHMANTO ANINDITO DAN RIE YANTI. TELAGA BAHASA,(7), 2, 195-206.

Iye, R. WRITING SKILLS IN SMP USWATUN HASANAH, BURU DISTRICT. 
Iye, R. Jl Prof Dr HAR Basalamah No, and Namlea-Kab Buru.". TUTURAN DALAM PROSESI LAMARAN PERNIKAHAN DI TOMIA KABUPATEN WAKATOBI." Kontemporer. Bandung: PT Remaja.

Karim, K., Maknun, T., \& Abbas, A. (2019). Praanggapan Dalam Pamflet Sosialisasi Pelestarian Lingkungan Di Kabupaten Wakatobi. Jurnal Ilmu Budaya, 7(2), 241-247.

Lafamane, F. (2020). Tata Bahasa Sistemik Fungsional (Suatu Pandangan).

Lafamane, F. (2020). Perkembangan Teori Sastra (suatu Pengantar). OSF Preprints. July, 25.

Lafamane, F. (2020). Tata Bahasa Fungsional (functional Grammar).

Lafamane, F. (2020). Fenomena Penggunaan Bahasa Daerah di Kalangan Remaja.

Mansyur, F. A., \& Suherman, L. A. (2020). The Function of Proverbs as Educational Media: Anthropological Linguistics on Wolio Proverbs. ELS Journal on Interdisciplinary Studies in Humanities, 3(2), 271-286.

Rahayaan, I., Azwan, A., \& Bugis, R. (2016). The Students' Writing Ability through Cooperative Script Method. Jurnal Retemena, 2(2).

Sadat, A., Nazar, A., Suherman, L. O. A., Alzarliani, W. O. D., \& Birawida, A. B. (2019, October). Environmental care behavior through e-jas model with science edutainment approach. In IOP Conference Series: Earth and Environmental Science (Vol. 343, No. 1, p. 012126). IOP Publishing.

Sadat, A., Sa'ban, L. M. A., Suherman, L. O. A., Bahari, S., Ibrahim, T., \& Zainal, M. (2019, October). Internalization characters of environmental care and disaster response through care partner schools. In IOP Conference Series: Earth and Environmental Science (Vol. 343, No. 1, p. 012125). IOP Publishing.

Salamun, T. (2018). DEIKSIS PERSONA BAHASA INDONESIA DIALEK AMBON [Personal Deixes of Indonesian Leanguage With Ambonese Dialect]. Totobuang, 5, 325-339.

Salamun, T. (2018). RELASI KEKERABATAN BAHASA HITU, WAKAL, MORELA, MAMALA, DAN HILA DI PROVINSI MALUKU [The Family Relationship Language Hitu, Wakal, Morela, Mamala, and Hila in Maluku Province].

Suherman, L. A. (2018). The Analysis of Metaphorical Domain on English "Stab Verb" in Corpora. ELS Journal on Interdisciplinary Studies in Humanities, 1(1), 52-58.

Suherman, L. O. A., Salam, S., Mursanto, D., Efendi, A., Bahar, S. B., \& Kanna, T. (2019, October). The effect of open-air curing on compressive strength of geopolymer mortar containing laterite soil and slaked lime. In IOP Conference Series: Earth and Environmental Science (Vol. 343, No. 1, p. 012133). IOP Publishing.

Susiati, S., \& lye, R. (2018). Kajian Geografi Bahasa dan Dialek di Sulawesi Tenggara: Analisis Dialektometri. Gramatika: Jurnal IImiah Kebahasaan dan Kesastraan, 6(2), 137-151. 
Susiati, S. Dialektometri Segitiga: Hubungan Kekerabatan Bahasa Di Sulawesi Tenggara (Bahasa Wakatobi, Bahasa Cia-Cia, Bahasa Pancana, Bahasa Kioko, Bahasa Tolaki).

Susiati, S., lye, R., \& Suherman, L. O. A. (2019). Hot Potatoes Multimedia Applications in Evaluation of Indonesian Learning In SMP Students in Buru District. ELS Journal on Interdisciplinary Studies in Humanities, 2(4), 556-570.

Susiati, S. (2018). Homonim bahasa kepulauan tukang besi dialek kaledupa di kabupaten wakatobi [the homonymon of tukang besi island languange in kaledupa dialect at wakatobi regency]. Totobuang, 6 (1), 109, 123.

Susiati, S. (2020). Emosi Verbal Suku Bajo Sampela.

Susiati, S. (2020). Fenomena Tuturan Emosi Verbal Bahasa Indonesia Suku Bajo Sampela.

Susiati, S. (2020). Nilai Budaya Suku Bajo Sampela Dalam Film The Mirror Never Lies Karya Kamila Andini.

Susiati, S. (2020). Konsep Pertentangan Dalam Film" Aisyah Biarkan Kami Bersaudara" Karya Herwin Novianto.

Susiati, S. (2020). Strategi AMBT untuk Meningkatkan Kemampuan Membaca Pemahaman Interpretatif Siswa Kelas IV SD Negeri 3 Namlea Kabupaten Buru.

Susiati, S. (2020). Fungsi Konatif Pada Iklan Mesin Cuci Hole-Less Tub Dari Sharp: Analisis Wacana Kritis.

Susiati, S. (2020). GAYA BAHASA SECARA UMUM DAN GAYA BAHASA PEMBUNGKUS PIKIRAN.

Susiati, S. (2020). The Concept Of Togetherness In The Films" Aisyah Biarkan Kami Bersaudara" By Herwin Novianto.

Susiati, S. (2020). Konsep Kebersamaan Dalam Film" Aisyah Biarkan Kami Bersaudara" Karya Herwin Novianto.

Susiati, S. (2020). Teori dan Aliran Linguistik: Tata Bahasa Generatif.

Susiati, S. (2020). Metode Pembelajaran Bahasa Indonesia: Sosiodrama.

Susiati, S. (2020). Rekontruksi Internal Bahasa Bugis dan Bahasa Makassar: Linguistik Komparatif.

Susiati, S. Bahan Ajar: Psikolinguistik.

Susiati, S. (2020). PENTINGNYA MELESTARIKAN BAHASA DAERAH.

Susiati, S. (2020). Morfologi Kelas Kata Dalam Bahasa Indonesia.

Susiati, S. (2020). Semantik: Teori Semantik, Relasi Makna, Marked, Dan Unmarked. 
Susiati, Y. T. Risman Iye. A. Kesantunan Imperatif Bahasa Indonesia Suku Bajo Sampela: Balai Pembinaan dan Pengembangan Bahasa. 2018. Kongres Bahasa Indonesia (No. 12, pp. 1-6). Report.

Susiati, S. (2020). Internal Recontruction Bugis Language and Makassar Language.

Susiati, S. (2020). Kesantunan Imperatif Bahasa Melayu Ambon.

Susiati, S. (2020). Gaya Bahasa Secara Umum Dan Gaya Bahasa Pembungkus Pikiran: Stilistika.

Susiati, S. (2020). Tuturan Kesantunan Imperatif Bahasa Indonesia Suku Bajo Sampela.

Susiati, S. (2020). Nilai Budaya Suku Bajo Sampela Dalam Film The Mirror Never Lies Karya Kamila Andini.

Susiati, S. (2020). Pengaplikasian Multimedia Hot Potatoes Dalam Evaluasi Pembelajaran Bahasa Indonesia Pada Siswa SMP Negeri 9 Buru.

Susiati, S., \& lye, R. (2018). Kajian Geografi Bahasa dan Dialek di Sulawesi Tenggara: Analisis Dialektometri. Gramatika: Jurnal IImiah Kebahasaan dan Kesastraan. 6 (2), 137-151.

Susiati, S. (2020). Kaidah Fonologi Bahasa Indonesia.

Susiati, S. (2020). Wujud Morfologi Bahasa Indonesia.

Susiati, S. (2020). Makian Bahasa Wakatobi Dialek Kaledupa.

Susiati, S. (2020). Eksistensi Manusia Dalam Film" Aisyah Biarkan Kami Bersaudara" Karya Herwin Novianto.

SUSiati, S. NILAI BUDAYA SUKU BAJO SAMPELA DALAM FILM THE MIRROR NEVER LIES.

Susiati, S. (2020). Konsep Keterasingan Dalam Film" Aisyah Biarkan Kami Bersaudara" Karya Herwin Novianto.

Susiati, S. (2020). Concept Of Conflict In The Films "AISYAH BIARKAN KAMI BERSAUDARA" By Herwin Novianto.

Susiati, S. (2020). Embrio Nasionalisme Dalam Bahasa dan Sastra.

Susiati, S. PERWUJUDAN SIMILE OLEH MERARI SIREGAR DALAM NOVEL AZAB DAN SENGSARA.

Susiati, S. (2020). Nilai Pembentuk Karakter Masyarakat Wakatobi Melalui Kabhanti Wa Leja.

Tahir, S. Z. A. B. (2017). Pengembangan Materi Multibahasa untuk Siswa Pesantren. Unpublish dissertation.

Tahir, S. Z. B. (2015). Multilingual Teaching And Learning At Pesantren. 14 Asian EFL Journal Conference. 
Tenriawali, A. Y. (2018). Representasi korban kekerasan dalam teks berita daring tribun timur: analisis wacana kritis [the representation victims of violence in tribun timur online news text: critical discourse analysis]. TOTOBUANG, 6 (1), 1, 15.

Yusdianti, A. (2020). THE REPRESENTATION VICTIMS OF VIOLENCE IN TRIBUN TIMUR ONLINE NEWS TEXT: CRITICAL DISCOURSE ANALYSIS.

Verhaar, J.W.M.1999 Asas-asas Linguistik Umum, Gajah Mada University Press. Yogyakarta. Hal 3-8. 